\title{
25 Research Square \\ Feasibility of a Multidisciplinary Lifestyle Program for Obese Patients With Atrial Fibrillation
}

Nicole Tenbult - van Limpt ( $\square$ nicole.van.limpt@mmc.nl )

Maxima Medisch Centrum https://orcid.org/0000-0002-9021-9895

JJ Kraal

Technische Universiteit Delft

RWM Brouwers

Maxima Medisch Centrum

RF Spee

Maxima Medisch Centrum

SCM Eijsbouts

Maxima Medisch Centrum

HMC Kemps

Maxima Medisch Centrum

Research

Keywords: Lifestyle, cardiac rehabilitation, atrial fibrillation, obesity

Posted Date: August 26th, 2020

DOI: https://doi.org/10.21203/rs.3.rs-62346/v1

License: (c) (i) This work is licensed under a Creative Commons Attribution 4.0 International License.

Read Full License 


\section{Abstract}

Aims: Atrial Fibrillation (AF) is often associated with obesity. The effects of traditional lifestyle programs are often not maintained in the longer term effects because the programs do not sufficiently focus on behavioral change. We want to study the feasibility of a multidisciplinary lifestyle program, cardiac rehabilitation (CR) focusing on behavioral change in patients with AF and obesity.

Methods and results: Patients received CR for three months including exercise training, lifestyle counseling by an Advanced Nursing Specialist, dietary advice and psychosocial therapy when deemed necessary. Main endpoints were weight loss and burden of AF (AFSS questionnaire). Secondary endpoints were physical fitness (6MWT), depression (PHQ9) and anxiety (GAD7). Measurements were performed at baseline and post-CR. Weight and 6MWT were also assessed at 1-year follow-up. After following a lifestyle program, patients improved their weight and physical condition, and were less symptomatic. The frequency of AF-related symptoms was considerably reduced immediately after rehabilitation and was even lower after 1 year. The severity of AF complaints post-CR was similar to the baseline, but significantly lower after 1 year.

Conclusion: A multidisciplinary lifestyle program with an emphasis on structural lifestyle improvement is feasible for obese patients with AF and potentially effective in reducing symptoms, weight and physical fitness, thereby decreasing the burden of AF.

\section{What's New}

- These findings suggests that structural lifestyle improvement results in permanent weight loss and thus a decrease in AF complaints

- Weight reduction using a cardiac rehabilitation program can be an important treatment option for obese patients before invasive treatment is initiated

- Successful implementation of lifestyle programs for patients with AF and obesity can have important implications for the treatment and prevention of AF and associated (healthcare) costs

- AF can be a serious health threat due to underlying cardiovascular diseases and thromboembolic risks. It is essential to not only pay attention to the treatment of AF, but also to take into account possible risk factors and lifestyle behavior that can cause or worsen

\section{Introduction}

The number of patients with chronic cardiac disease, including atrial fibrillation (AF) has been increasing substantially in recent years. Currently, the prevalence of $A F$ is $2 \%$ and the lifetime risk is estimated at 1 in $3[1,2,3,4]$. AF is caused by structural changes in the atria. These can occur as a result of aging and often occur in combination with underlying cardiovascular diseases such as hypertension, heart failure and coronary artery disease. AF is often associated with overweight and obesity. Both disorders have been 
identified as major global epidemics that are also associated with increased mortality and morbidity. Obesity has adverse effects on the hemodynamics, structure and function of the heart, so that the prevalence of AF in people with obesity is high [3,4]. In addition, patients with AF and obesity often have more complaints and a faster progression of AF compared to patients with a normal weight [5]. Sustainable weight loss is associated with a decrease in symptoms of $\mathrm{AF}[6,7]$.

Lifestyle improvement and physical training can lead to weight loss, thereby reducing AF complaints and improving quality of life [6]. In addition, a higher fitness level increases the chance of success of Pulmonary Vein Isolation (PVI) [8]. During PVI, the four pulmonary veins are electric isolated, by scarring or destroying tissues that serve as a trigger for AF. The ESC guidelines for the management of atrial fibrillation recommend $\mathrm{PVI}$ for obese patients with $\mathrm{AF}$, in combination with lifestyle changes that lead to weight reduction [9]. However, the effects of traditional lifestyle programs are often not maintained in the longer term because the programs do not sufficiently focus on behavioral change [10]. In addition, only a small proportion of patients with AF are included in CR programs, despite the proven clinical benefits of such programs $[11,12]$. CR focuses on restoring the physical condition, improving lifestyle and psychological support during this process. Although at the start of CR more than $80 \%$ of patients are overweight and more than $50 \%$ have metabolic syndrome [13]. Most CR programs do not contain a program specifically aimed at weight loss $[13,14]$. In addition, the importance of structural lifestyle improvement is insufficiently emphasized in such programs. Therefore, adding a lifestyle program for overweight and AF patients could further improve the results of CR [7]. We hypothesize that adopting a structural lifestyle improvement results in permanent weight loss and thus a decrease in AF complaints. In this pilot we want to investigate the feasibility of a lifestyle program for overweight AF patients focused on sustainable behavioral change.

\section{Methods}

\section{Participants}

Patients with AF who presented at the Cardiac Rehabilitation Unit of Centre FLOW, Máxima MC in Veldhoven / Eindhoven in 2016 and 2017 were eligible for participation. Patients with AF and overweight were referred by the cardiologist and subsequently invited for an intake procedure with an Advanced Nursing Specialist. Before the start of the study an ECG was made for each patient, and the left ventricular function, lipids and $\mathrm{HbA} 1 \mathrm{c}$ were determined. All patients were screened for motivation, trainability and practical possibilities. To personalize the lifestyle program, patients were asked to formulate personal goals. These personal goals were leading for the lifestyle program. We aimed to include 10 patients.

$\underline{\text { Inclusion and exclusion criteria }}$

Patients with symptomatic AF and a BMI higher or equal to 29 were asked to participate in the lifestyle program. Contra-indications for participation in the lifestyle program included progressive symptoms of heart failure, myocardial ischaemia during exercise testing (ST depression of $\geq 2 \mathrm{~mm}$ ), sinus tachycardia 
at rest with a frequency of more than 110 beats per minute $(\mathrm{bpm})$ or atrial fibrillation with a frequency > $100 \mathrm{bpm}$ at rest and severe cognitive impairment (memory, attention, concentration and psychiatric disorders).

\section{$\underline{\text { Intervention }}$}

Before the start of the exercise program, an individual program was composed together with the patient based on their exercise capacity and personal goals. The first six weeks of the program consisted of two training sessions per week, the six weeks thereafter once a week. Blood pressure and heart rate were checked before, during and after the training. The training sessions consisted of aerobic training (treadmill, bicycle ergometer) and strength training and lasted about 60 minutes. In addition to the exercise program, all patients received an individual intake with a dietitian and an individual intake with a psychologist. If indicated, additional follow-up was planned with the dietitian and / or psychologist. Finally, patients were able to participate in a relaxation module consisting of breathing exercises and body awareness and learning relaxation techniques aimed at creating more moments of rest and learning to cope better with stress.

After three months, the program and progress were evaluated with the Advanced Nursing Specialist where personal goals were discussed. The patient received advice on the continuation of the active lifestyle and possible follow-up appointments with the doctor and / or fitness center. A final evaluation took place 12 months after the start of the program.

\section{Main outcomes and measures}

The primary endpoint of the study was feasibility of the lifestyle program, defined as the \% of patients that completed the intervention. Secondary endpoints were weight and severity of the complaints associated with AF. The severity of AF has been questioned with the Atrial Fibrillation Severity Scale (AFSS) questionnaire, a validated Canadian questionnaire about AF complaints [15,16]. Other secondary endpoints were physical capacity, depression, and anxiety symptoms. Physical capacity was measured using the six-minute walking test (6MWT) and 1-RM. 6MWT was performed in a 25-meter corridor at a speed of the patients' preference with the instruction to cover the greatest possible distance during 6 min without running. The 1-repetition maximum (1-RM), a measure of muscle strength, was defined as the weight that can be pushed or lifted a maximum of once. Anxiety and depression complaints were queried using validated questionnaires (PHQ and GAD-7) $[17,18]$. These questionnaires are recommended by the cardiac rehabilitation guidelines [19]. The primary and secondary outcome measures were measured at the start of the program and after three and 12 months.

\section{Analysis}

The general characteristics of the participants were analysed on the basis of descriptive statistics. Changes in endpoints over time were analysed using paired t-tests. The analyses were performed in SPSS (IBM 24.0). 


\section{Results}

A total of 10 patients participated in this study. The majority of patients were male (8/2), the mean age was $57.2 \pm 9.0$ and the BMI $32.4 \pm 3.5 \mathrm{~kg} / \mathrm{m} 2$ (Table 1). Two patients did not complete their CR program, both because of private problems. Exercise capacity and muscle strength could not be determined during follow-up in three patients due to recent PVI, neck hernia, and shoulder and knee complaints, respectively.

The most important outcomes are described in Table 2. After CR there was a weight decrease from 107.2 $\pm 11.8 \mathrm{~kg}$ to $102.5 \pm 13.7 \mathrm{~kg}(p=0.01)$. However, there was no significant weight loss 1 year after participation compared to baseline $(p=0.09)$. The frequency of AF complaints was considerably reduced immediately after rehabilitation $(p=0.01)$, and this was also lower at 12 months $(p=0.02)$. Compared to baseline, the severity of AF complaints was comparable for three months $(p=0.18)$, but significantly lower at 12 months follow-up $(p=0.02)$. Depression and anxiety scores were comparable between baseline and 3 months ( $p=0.16$ and $p=0.39$ respectively).

The distance walked on the 6MWT was significantly higher after CR, from $538.9 \pm 70.6$ meters to $595.3 \pm$ 72.8 meters $(p=0.01)$. 1-RM quadriceps measurements showed a non-significant increase in muscle strength immediately after rehabilitation, from $179.5 \pm 49.3 \mathrm{~kg}$ to $245.3 \pm 63.7 \mathrm{~kg}(p=0.15)$. At 12 months, muscle strength was significantly higher than baseline $(259.7 \pm 52.7 \mathrm{~kg}, \mathrm{p}<0.01)$. The 1-RM biceps and 1-RM triceps also showed a non-significant increase in strength immediately after cardiac rehabilitation (biceps: from $22.1 \pm 8.9 \mathrm{~kg}$ to $25.6 \pm 6.0 \mathrm{~kg}(\mathrm{p}=0.10)$, triceps: from $27.1 \pm 9.7 \mathrm{~kg}$ to $35.6 \pm$ $6.8 \mathrm{~kg}(\mathrm{p}=0.06))$. Also for the biceps and triceps the measurement after 1 year was significantly higher than before the start of the heart rehabilitation (biceps: $29.8 \pm 3.4, p=0.29$, triceps: $39.6 \pm 2.5, p=0.20$ ).

\section{Table 1: baseline characteristics of study group}

\begin{tabular}{|c|c|c|}
\hline \multicolumn{2}{|c|}{ Age (years) } & $57.2 \pm 9.0$ \\
\hline \multicolumn{2}{|c|}{$\operatorname{Man}(\mathrm{n})$} & 8 \\
\hline \multicolumn{3}{|c|}{ Anthropometry } \\
\hline- & Weight (kg) & $107.2 \pm 11.8$ \\
\hline - & $\mathrm{BMI}(\mathrm{kg} / \mathrm{m} 2)$ & $32.4 \pm 3.5$ \\
\hline
\end{tabular}

Data is displayed as mean $\pm S D$

Table 2: Outcome measures at baseline, discharge (3 months) and follow-up (12 months) after CR 


\begin{tabular}{|c|c|c|c|c|c|}
\hline & Baseline & $\begin{array}{l}\text { After } 3 \\
\text { months }\end{array}$ & $\begin{array}{l}\text { After } 12 \\
\text { months }\end{array}$ & $\begin{array}{l}\text { p-value } 0-12 \\
\text { weeks }\end{array}$ & $\begin{array}{l}\mathrm{p} \text {-value } 0-52 \\
\text { weeks }\end{array}$ \\
\hline Weight (kg) & $\begin{array}{l}107.2 \pm \\
11.8\end{array}$ & $\begin{array}{l}102.5 \pm \\
13.7\end{array}$ & $105.1 \pm 16.1$ & 0.01 & 0.09 \\
\hline AFSS frequency & $35.6 \pm 3.8$ & $31.2 \pm 3.3$ & $24.8 \pm 3.2$ & 0.01 & 0.02 \\
\hline AFSS severity & $20.0 \pm 3.7$ & $16.6 \pm 3.3$ & $9.3 \pm 3.6$ & 0.18 & 0.02 \\
\hline $6 \mathrm{MWT}(\mathrm{m})$ & $\begin{array}{l}538.9 \pm \\
70.6\end{array}$ & $\begin{array}{l}595.3 \pm \\
72.8\end{array}$ & $600.8 \pm 94.0$ & 0.01 & 0.10 \\
\hline PHQ9 & $6.8 \pm 4.3$ & $4.6 \pm 4.3$ & - & 0.16 & - \\
\hline GAD7 & $4.4 \pm 5.3$ & $2.7 \pm 2.9$ & - & 0.39 & - \\
\hline $\begin{array}{l}\text { 1-RM quadriceps } \\
(\mathrm{kg})\end{array}$ & $\begin{array}{l}179.5 \pm \\
49.3\end{array}$ & $\begin{array}{l}245.3 \pm \\
63.7\end{array}$ & $259.7 \pm 52.7$ & 0.15 & 0.00 \\
\hline 1-RM biceps (kg) & $22.1 \pm 8.9$ & $25.6 \pm 6.0$ & $29.8 \pm 3.4$ & 0.10 & 0.29 \\
\hline 1-RM triceps $(\mathrm{kg})$ & $27.1 \pm 9.7$ & $35.6 \pm 6.8$ & $39.6 \pm 2.5$ & 0.06 & 0.20 \\
\hline
\end{tabular}

Data is displayed as mean \pm SD

\section{Discussion}

This study shows that a lifestyle program focused on sustainable behavioral change in overweight AF patients is feasible. Of the included patients, $80 \%$ completed the entire program. In addition, both the frequency and the severity of the complaints associated with AF decreased significantly after 1 year. The weight and the maximum walking distance, on the other hand, only showed a temporary improvement. Although no significant weight loss was demonstrated in our study, we still observed a reduction in the severity and frequency of AF complaints.

Although the size of our patient population was small, the positive results after participating in the rehabilitation program are comparable to other studies. Various studies show that lifestyle guidance or lifestyle interventions for patients with AF and overweight ensure that they suffer less from AF and reduce both the severity and frequency of AF [20]. The LEGACY study showed that targeted weight reduction in AF resulted in a reduction in the severity and frequency of AF. In patients with obesity and symptomatic $\mathrm{AF}, \mathrm{Abed}$ et al also demonstrated that weight reduction with an intensive risk management program resulted in a reduction in the burden and frequency of AF [8]. Compared to other studies, patients in this new lifestyle program for AF were individually screened for motivation and trainability at intake and accompanied by an Advanced Nursing Specialist, dietitian and Medical Psychologist throughout the lifestyle program. Based on personal goals, a program was compiled with explicit attention to motivating structural behavioural change. For this reason we expect that this intervention could lead to higher adherence and therefore also to better long-term results and better efficiency than less personalized, one- 
size-fits-all programs. As far as we know, there is no data from previous studies on participation and compliance with regard to lifestyle programs in this specific population.

Successful implementation of lifestyle programs for patients with AF and overweight can have important implications for the treatment and prevention of AF and associated (healthcare) costs. AF can be a serious health threat due to underlying cardiovascular diseases and thromboembolic risks. It is essential to not only pay attention to the treatment of $A F$, but also to take into account possible risk factors and lifestyle behaviour that can cause or worsen AF. Halle et al. [21] confirm in the HUNT3 survey that obesity is a risk factor for AF. Moreover, this survey shows that high physical activity has a preventative effect on the development of AF. Our research also shows that the frequency of AF complaints decreased considerably immediately after rehabilitation and after 12 months of follow-up. In addition, weight reduction using a cardiac rehabilitation program can be an important treatment option for obese patients before invasive treatment is initiated. As such, an aggressive approach to cardiovascular risk factors was shown to improve the long-term success of AF ablation [22]. Moreover, prevention is potentially cheaper than invasive treatment strategies and it also reduces the burden of disease for each individual patient. Policy makers should therefore be more committed to financial resources to develop lifestyle programs that focus on sustainable lifestyle improvement.

A limitation of this research is the number of data that was available for analysis. Although the study was set up as a feasibility pilot, a number of measurements could not be performed due to comorbidity and other physical complaints. Therefore, the results of the statistical analyses must be interpreted with caution. Nevertheless, the measurements that were available do provide an overall positive image of the cardiac rehabilitation program for patients with AF and overweight. A second limitation is the use of the overweight diagnosis for patients with AF. Although BMI and other clinical measurements are useful indications for overweight, measuring epicardial fat could have added value to the cardiometabolic risk profile of patients. Epicardial fat can be easily assessed using non-invasive imaging techniques. A growing number of data from epidemiological and clinical studies have shown that epicardial fat is consistently associated with the presence, severity and recurrence of AF [23]. This data may also be investigated in future studies.

\section{Conclusion}

For obese patients with AF, a multidisciplinary lifestyle program is a feasible and potentially effective treatment for reducing the burden and severity of $A F$, improving fitness and long-term weight loss. A multicenter study is currently being conducted to study the clinical effectiveness of a customized cardiac rehabilitation program for obese AF and non-AF patients. The results of this study are expected in 2020 .

\section{Declarations}

\section{Ethics approval and consent to participate}

The study was submitted and approved by the Medical Ethics Committee of Máxima MC, the 
Netherlands. The study was conducted in accordance with the Declaration of Helsinki. All patients provided written informed consent before study entry.

Consent for publication

Not applicable.

Availability of data and materials

Not applicable.

Competing interests

The authors declare that they have no competing interests.

\section{Funding}

The study did not receive funding.

\section{Authors' contributions}

NT participated in the design of the study, conducted the trial and drafted the manuscript. JK and HK participated in the design of the study and helped to draft the manuscript. RS, SE and RB helped to revise the manuscript. All authors read and approved the final manuscript.

Acknowledgements

Not applicable.

\section{References}

1. Haissaguerre, $M$, Jais $P$, Shah, DC, et al. Spontaneous initiation of atrial fibrillation by ectopic beats originating in the pulmonary veins. N Engl J Med 1998;339:659-66.

2. Morillo, CA, Banerjee, A, Perel, P, et al. Atrial fibrillation: the current epidemic. J Geriatr Cardiol. 2017 Mar; 14(3): 195-203.

3. Ceornodolea, A, Bal, R, Severens, J, et al. Epidemiology and Management of Atrial Fibrillation and Stroke: Review of Data from Four European Countries. Stroke Res Treat. 2017; 2017: 8593207.

4. Lavie, CJ, Pandey A, Lau DH, et al. Obesity and Atrial Fibrillation Prevalence, Pathogenesis, and Prognosis: Effects of Weight Loss and Exercise. J Am Coll Cardiol. 2017 Oct 17;70(16):2022-2035. doi: 10.1016/j.jacc.2017.09.002.

5. Chrishan, JN, Sanders, P, Kottkamp, H, Kalman, JM. The role of obesity in atrial fibrillation European Heart Journal. Volume 37, Issue 20, 21 May 2016, Pages 1565-1572,

6. Lowres, N, Neubeck, L, Freedman, BS, et al. Lifestyle risk reduction interventions in atrial fibrillation: a systematic review. European Journal of Preventive Cardiology, vol. 19, 5: pp. 1091-1100. , First Published September 7, 2011.

7. Pathak, RK, Middeldorp, ME, Meredith, M, et all. Long-term Effect of Goal Directed Weight Management in an Atrial Fibrillation cohort: a long-term follow-up study (LEGACY). J Am Coll Cardiol 
2015; 65: 2159-69

8. Abed, HS, Wittert, GA, Leong, DP, et al. Effect of weight reduction and cardiometabolic risk factor management on symptom burden and severity in patients with atrial fibrillation: a randomized clinical trial. JAMA 2013; 310: 2050-60

9. https://www.escardio.org/static_file/Escardio/Guidelines/Publications/AFIB/d8021_Summary_AFib2016_Final.pdf

10. Middleton, KR, Anton, SD, Perri, MG. Long-Term Adherence to Health Behavior. Change Am J Lifestyle Med. 2013 Nov-Dec; 7(6): 395-404.

11. De Vries, H, Kemps, HMC, Van Engen-Verheul, M, et al. Cardiac rehabilitation and survival in a large representative community cohort of Dutch patients. European Heart Journal Advance Access published April 17, 2015

12. Van Engen-Verheul, $M$, De Vries, $H$, Kemps, HMC, et al. Cardiac rehabilitation uptake and its determinants in the Netherlands. First Published February 8, 2012 Research Article

13. Ades, PA, Savage, PD, Harvey-Berino, J. The Treatment of Obesity in Cardiac Rehabilitation. J Cardiopulm Rehabil Prev. 2010 Sep-Oct; 30(5): 289-298.

14. Menezes AR, Lavie CJ, De Schutter A, et al. Lifestyle modification in the prevention and treatment of atrial fibrillation. Prog Cardiovasc Dis. 2015 Sep-Oct;58(2):117-25. doi: 10.1016/j.pcad.2015.07.001. Epub 2015 Jul 13.

15. Mitchell, B, Roy, D, Skanes, AC, et al. Cardiovascular Society Severity in Atrial Fibrillation (CCS-SAF) Scale Validation of a New Simple Scale to Measure Symptoms in Atrial Fibrillation. Circ Arrhythm Electrophysiol. published online March 31, 2009;

16. Dorian, P, Guerra, PG, Kerr, CR, et al. Validation of a New Simple Scale to Measure Symptoms in Atrial Fibrillation The Canadian Cardiovascular Society Severity in Atrial Fibrillation Scale. Circulation: Arrhythmia and Electrophysiology. 2009;2:218-224 Originally published June 16, 2009

17. Kroenke, K, Spitzer, RL, Williams, JBW, et al. The Patient Health Questionnaire Somatic, Anxiety, and Depressive Symptom Scales: a systematic review. Gen Hosp Psychiatry 2010;32:345-59.

18. Spitzer, RL, Kroenke, K, Williams, JB, et al. A brief measure for assessing generalized anxiety disorder: the GAD-7. Arch Intern Med 2006; 166(10):1092-1097. PMID: 16717171

19. Revalidatiecommissie Nederlandse Vereniging Voor Cardiologie / Nederlandse Hartstichting (Richtlijn Hartrevalidatie 2004), Projectgroep PAAHR (gedeeltelijke herziening 2011)

20. Gallagher, C. Hendriks, JML, Mahajan, R, et al. Lifestyle management to prevent and treat atrial fibrillation. Expert Review of Cardiovascular Therapy http://dx.doi.org/10.1080/14779072.2016.11795812016

21. M, Haykowsky, M. Atrial fibrillation: A preventable lifestyle disease! European Journal of Preventive Cardiology, 2018

22. Pathak, RK, Middeldorp, ME, Lau, DH, et al. Aggressive risk factor reduction study for atrial fibrillation and implications for the outcome of ablation: the ARREST-AF cohort study. J Am Coll Cardiol. 2014 
Dec 2;64(21):2222-31. doi: 10.1016/j.jacc.2014.09.028. Epub 2014 Nov 24.

23. Wong, CX, Sun, MT, Odutayo, A, et al. FRCP Associations of Epicardial, Abdominal, and Overall Adiposity With Atrial Fibrillation. Circ Arrhythm Electrophysiol. 2016;9 e004378. DOI: 10.1161/CIRCEP.116.004378

\section{Supplementary Files}

This is a list of supplementary files associated with this preprint. Click to download.

- WhatsnewIJBNPA.docx 